\title{
Rest-activity rhythms in small scale homelike care and traditional care for residents with dementia
}

\author{
Jeroen S. Kok ${ }^{*}$ (D), Ina J. Berg ${ }^{1}$, Gerwin C. G. Blankevoort ${ }^{1}$ and Erik J. A. Scherder ${ }^{2}$
}

\begin{abstract}
Background: An enriched environment for residents with dementia may have a positive effect on the rest-activity rhythm. A small scaled homelike special care unit might be such an enriched environment. The present study shows whether the rest-activity rhythm of residents with moderate to severe dementia responds positively to a transfer from a regular Special Care Unit (SCU) to a small scaled homelike SCU.

Methods: Initially, a group of 145 residents living in a regular SCU participated. Out of this group, 77 residents moved to a small scaled homelike SCU. This group was compared to the group of 68 residents that remained at the regular SCU. Rest-activity rhythm was assessed by means of actigraphy and observation scales before and after relocation.
\end{abstract}

Results: No significant main effects nor significant interaction effects in intradaily and interdaily activity were found for the data of 38 residents in the small scaled homelike SCU and 20 residents of the regular SCU. The effect sizes, however, ranged from small to large.

Conclusions: Considering the effect sizes, a new study with a larger number of participants is necessary before firm conclusions can be drawn.

Trial registration: Current Controlled Trials ISRCTN11151241. registration date: 21-06-2017. Retrospectively registered.

Keywords: Dementia, Long term care, Nursing home, Actigraphy, Circadian rhythm

\section{Background}

Circadian rhythm disturbances, e.g. disturbances in the sleep-wake rhythm, are characteristic for aging [1], but even more so for elderly residents with dementia; circadian rhythm disturbances tend to become more severe with the progression of dementia [2-4].

A circadian rhythm is a rest-activity cycle over one day and is important for optimal functioning of an individual [5]. Observed rest-activity disturbances are long nocturnal awakenings, reduced total sleep/ sleep efficacy, restlessness [6], rapid eye movement disorders [7] and can be associated with daytime sleepiness and daytime napping [8].

Disturbances in the sleep-wake rhythm, in particular disturbed sleep during the night [9] irrespective of the

\footnotetext{
* Correspondence: js.kok@lentis.nl

${ }^{1}$ Lentis|Dignis, Mental Health Care Institute, PO Box 128, 9470 AC, Zuidlaren,

The Netherlands

Full list of author information is available at the end of the article
}

type of dementia [10], is primarily a burden for the residents themselves but also for the caregivers [11, 12].

Importantly, there appears to be a close relationship between rest-activity rhythm disturbances and cognitive and behavioral dysfunctions in dementia [13, 14]. For example, residents with increased nighttime restlessness show more disturbances in executive function, memory and attention [15-18]. They also show more behavioral problems $[19,20]$. Together, these clinical consequences require more intensive care [21].

It has been suggested that rest-activity rhythm disturbances might be due to a lower daytime activity level, reduced exposure to bright light, and decreased level of personal contact [22, 23]. An enriched environment can have positive effects and implies a certain level of qualitative and quantitative mental demands $[24,25]$, reflected in e.g. an increase in exposure to bright light during the day [13], a reduction of noise and light at 
nighttime [26] and specific social interventions [27] appear to improve the overall rest-activity rhythm and reduce daytime behavioral disturbances of residents with dementia [28]. Treating disturbed activity levels with psychosocial treatment, i.e. stimulation of social activities and the use of communication techniques $[9,27]$ and other therapies as bright light therapy at daytime [2] might relieve the work load of those who care for residents with dementia. A more stable restactivity will also improve the quality of life of residents with dementia as the rest-activity rhythm is strongly associated with general wellbeing [29] and physical and social activity [9].

Next to a higher activity level and more bright light exposure during daytime, also other types of 'enriched environment' might be effective in regulating disturbances in the rest-activity rhythm of residents with dementia. One such example is a small scaled homelike Special Care Unit (SCU) for residents with dementia. These SCU's may provide a valuable contribution to the management of rest/activity disorders in this population. It has been observed that more daily activity in SCU's is related to a better sleep at night in residents with moderate to severe dementia [30]. Within a small scaled homelike SCU residents with dementia are encouraged to engage more in household activities like doing the laundry and cooking whereas in the more regular SCU, these services are centrally coordinated [31]. Furthermore, in small scaled homelike SCU's (only 7 to 8 residents per unit), residents have their own private (bed)room, with a better sleeping environment. In regular SCU's residents share their bedrooms with up to 5 residents, and live at wards with up to 20 to 30 other residents. In the small scaled homelike SCU's, nurses are trained in so-called psychosocial treatment, i.e. they are trained in detecting problems and focus on potential causes and treatments $[27,32]$. In sum, a small scaled SCU is a specific type of an 'enriched environment' and consequently might have a beneficial influence on the rest-activity rhythm of residents with dementia; increased activity in the form of more household activities, increased personal contact due to person centered psychosocial treatment and smaller groups $[9,23,27]$ and perhaps a better sleeping environment due to single bedrooms. An increased difference between day and night, by day time interventions, can result in a stronger rest-activity rhythm due to better time cues for the resident with dementia [33]. However, a recent review shows that no previous study has investigated whether living in a small scaled SCU differs from living at a regular SCU with respect to the rest-activity rhythm of residents with dementia [34].

Therefore, the goal of the present study was to examine whether the rest-activity rhythm of residents with dementia who transferred from a regular SCU to a small scaled unit, improved in comparison to those who stayed at the regular SCU.

\section{Methods \\ Study design}

Quasi-experimental longitudinal field study with an intervention and a control group.

\section{Participants}

Inclusion criterion was a diagnosis of dementia, exclusion criterion was no dementia.

The diagnosis of dementia was made by a neurologist or geriatrician (medical file) and resulted in 186 potential participants. Initially 145 participants consented: small scaled homelike SCU $(n=77)$ and control group $(n=68)$. There were no significant differences in type of dementia between both groups (see Table 1). All residents suffered from a moderate to severe dementia. For a flowchart, see Fig. 1.

\section{Participant characteristics}

There were no significant differences in gender, age, education, SMMSE score and depression score for both groups at the start of the study (see Table 2). To determine the global level of functioning, the Dutch version of the Standard Mini Mental State Examination (SMMSE) was used [35, 36] (19 questions with a maximum of 30 points). For depressive symptoms, the Geriatric Depression Scale (GDS) was applied [37, 38] (15 questions (yes/no)). Demographic data of the investigated subjects has been used in earlier research [39].

\section{Procedure}

Initially all residents were institutionalized in two nursing homes (regular SCU's) of a mental health care institute in the Northern part of The Netherlands. The intervention group moved from a regular SCU with wards up to 20-30 residents and bedrooms with a maximum of 5 residents to a small scaled homelike SCU. Residents in the small scaled homelike SCU had single bedrooms in separated homelike wards of 7-8

Table 1 Type of dementia of the participants

\begin{tabular}{lll}
\hline Type dementia & $\begin{array}{l}\text { Regular SCU group } \\
N(\%)\end{array}$ & $\begin{array}{l}\text { Small scale homelike } \\
\text { SCU group N (\%) }\end{array}$ \\
\hline Dementia nos & $26(38)$ & $18(23)$ \\
Alzheimer's dementia & $13(19)$ & $24(31)$ \\
Vascular dementia & $8(12)$ & $5(7)$ \\
Mixed dementia & $11(16)$ & $6(8)$ \\
Frontotemporal dementia & $4(6)$ & $0(0)$ \\
Lewy body dementia & $1(2)$ & $1(1)$ \\
Other* & $1(2)$ & $4(5)$ \\
\hline
\end{tabular}

*Alcohol dementia, corticobasal degeneration, Korsakov, Parkinson dementia, semantic dementia 


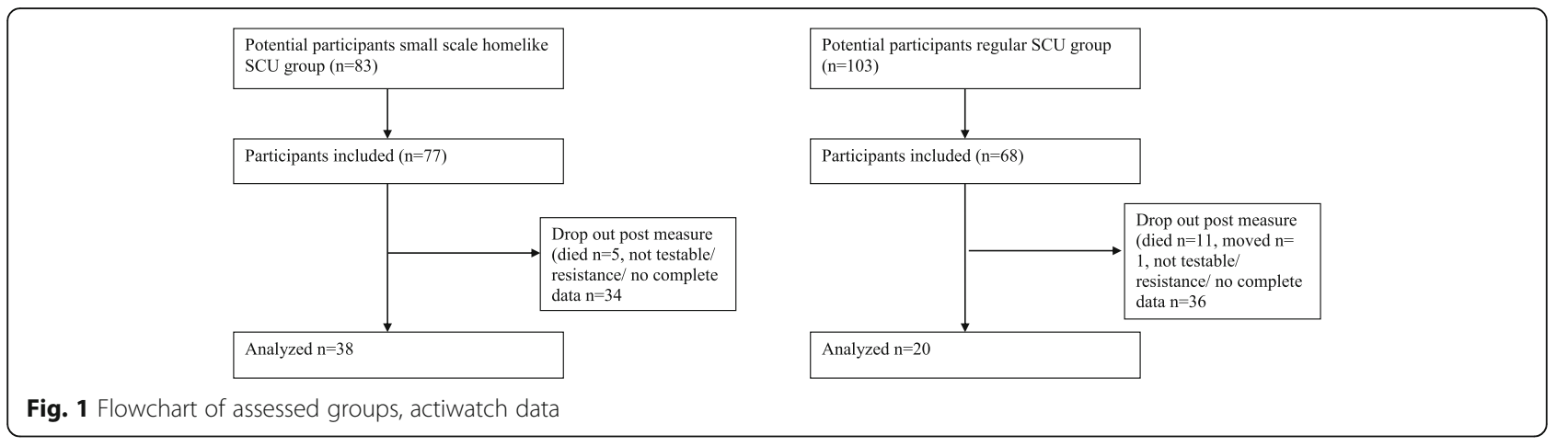

residents, situated in one large building and the nurses conceived a nine hour training focused on psychosocial treatment. The control group stayed at the regular SCU. Due to organizational reasons, one regular SCU was relocated. Rest-activity was measured with objective and subjective methods (see materials) three months before the relocation (baseline) and three months (post) and six months after relocation (follow-up).

\section{Informed consent}

Hundred-forty-five legal representatives gave written informed consent for the study and were informed about the goal and procedure of the study. The study has been approved by the Ethical Committee of the department of Psychology of the University of Groningen, the Netherlands (no. PPO008093), registered 3 June 2009. Before each measurement the resident was asked for consent. By resistance of any kind of the resident, no measurements were conducted.

\section{Materials \\ Actigraphy}

Objective rest-activity variables, measured by wrist movement, were assessed with an Actiwatch (Cambridge Neurotechnology Ltd., Cambridge, UK) [40], a small activity monitor with a relatively high accuracy [41]. This device contains a sensor which records intensity, amount and duration of movement in three directions. The activity of the subjects was recorded every minute, day and night, for 7 days.

The following variables were assessed: Intra daily variability (IV) shows the continuity or fragmentation of sleep-activity rhythm in $24 \mathrm{~h}$, i.e., the extent of transitions and the frequency between rest and activity. Lower values are an indication of a normal rest-activity pattern. Interdaily Stability (IS) is a measure which compares all included $24 \mathrm{~h}$ periods from day to day (the predictability of the $24 \mathrm{~h}$ rest-activity pattern) and is calculated as the ratio between the variance of the average $24 \mathrm{~h}$ pattern around the mean and overall variance. Higher scores indicate a stable rhythm between days. Amplitude shows the intensity of activity or movement. A higher score represents more activity. Relative Amplitude (RA) serves as a measure of the relative difference (mean) in movement between the 5 least active hours (L5) and the 10 most active hours (M10) within an average $24 \mathrm{~h}$ pattern. A higher score indicates a better rhythm; a larger difference between daytime activity and night time rest. L5 represents the total activity of the 5 least active 5-h daily period (night-time rest) and M10 the total activity of the 10 most active 10-h daily period (daytime activity).

Only during showering the actiwatch was removed. A special strap prevented the subject removing the actiwatch. In case of lost periods (missing or invalid data), the actiwatch was placed for one more week. Incomplete recordings were excluded from analysis. Valid data was collected $7 \times 24$ h for each measurement.

The actiwatch was worn on the dominant arm during a 7-day period 3 months before the relocation (baseline), 3 months after relocation (post) and 6 months after relocation (follow-up). The control group was assessed in de same period of the year with the same time intervals.

\section{Observations by nursing staff}

Intersubjective activity level was assessed by using two scales of a behavioral observation scale for intramural psychogeriatry, namely restlessness and repetitive behavior (GIP) [42]. The GIP is an observation instrument which is validated to judge different behaviors of residents with dementia ( 4 points scale from (almost) always to never.

\section{Statistical analysis}

The raw data collected with the actiwatches were used for analysis with SPSS, version 24. Differences between both groups were analyzed by performing independent sample t-tests and partial eta square $t$ test (two tailed). The differences between the groups of the actigraph parameters and behavior observation scores were evaluated with a General Linear Model - multivariate variance analysis (MANOVA). $P$-values $<.05$ were considered as statistical significant. 
Table 2 Demographic characteristics of the participants at baseline for both groups 1 [47]

\begin{tabular}{llll}
\hline & $\begin{array}{l}\text { Regular SCU } \\
\text { group M (SD) }\end{array}$ & $\begin{array}{l}\text { Small scale homelike } \\
\text { SCU group M (SD) }\end{array}$ & Test statistic \\
\hline Sample size (n) & 48 & 67 & \\
Gender & F 32, M 16 & F 47, M 20 & $.158^{\text {a }}$ (n.s.) \\
Age (years) & $82.88(8.3)$ & $83.27(6.3)$ & $.772^{\text {c }}$ (n.s.) \\
Depression & $1.1(0.9)$ & $1.4(1.2)$ & $.272^{\text {c }}$ (n.s.) \\
Education $^{d}$ & $3.39(1.3)$ & $3.32(1.4)$ & $.782^{\text {c }}$ (n.s.) \\
SMMSE $^{\text {SMMS }}$ & $8.55(6.3)$ & $8.62(6.5)$ & $.961^{\mathrm{c}}$ (n.s.) \\
\hline
\end{tabular}

pearson chi square test, ${ }^{\mathrm{c}} \mathrm{t}$-test. (two-tailed), ${ }^{\mathrm{d}}$ Conform Verhage [53]

Eta squared was used as measure for effect size for group mean differences [43] (95\% CI) of which .01-.05 is considered as small effect size, .06-.13 as moderate and .14 and higher as large [44].

\section{Results}

In total, complete actiwatch data were obtained from 38 participants of the intervention group and 20 residents of the control group. Measurements were done for seven days $(7 \times 24 \mathrm{~h})$. Intersubjective measurements were obtained for 51 residents of the intervention group and 29 residents of the control group.

\section{Actigraphy}

For means and standard deviations of the actigraphic variables and interaction effects, see Table 3. Figure 2 shows line graphs for all variables.

\section{Main effects}

There are no significant differences between both groups for the dependent variables night time restlessness, daytime activity, intradaily variability, interdaily stability, amplitude and relative amplitude (see Table 3). This implicates there is no main effect in rest-activity rhythm between residents living in a small scale homelike SCU and residents living in a regular SCU over time. Calculated effect sizes are all small; night time restlessness (.02), daytime activity (.002), intradaily variability (.02), interdaily stability (.01), amplitude (.01) and relative amplitude (.03).

\section{Interaction effects}

Wilks' lambda score for interaction effects between the groups, showed two significant interactions effects (time $\mathrm{x}$ group) for intradaily variability and interdaily stability. The direction of the effect shows a better rest-activity pattern (intradaily stability) within $24 \mathrm{~h}$ for the experimental group and a more stable rhythm between days (interdaily stability) in the control group.

Four variables showed no significant interaction effects; night-time restlessness, day-time activity, amplitude and relative amplitude.

The pairwise comparisons for daytime activity and amplitude are significant for the pre - post measurements, implicating less daytime activity and a lower amplitude in the pre - post condition for both groups but not for the pre - follow up comparison. For the other variables there were no significant differences between pre - post or post - follow up.

Effect sizes (95\% CI, time x group) are large for interdaily stability (.16) and moderate for daytime

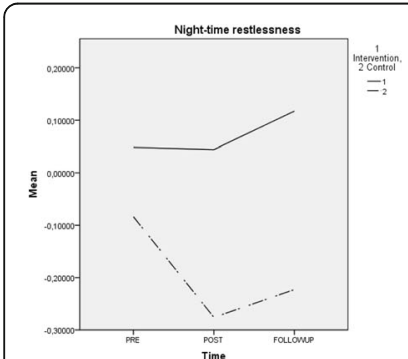

Daytime activity
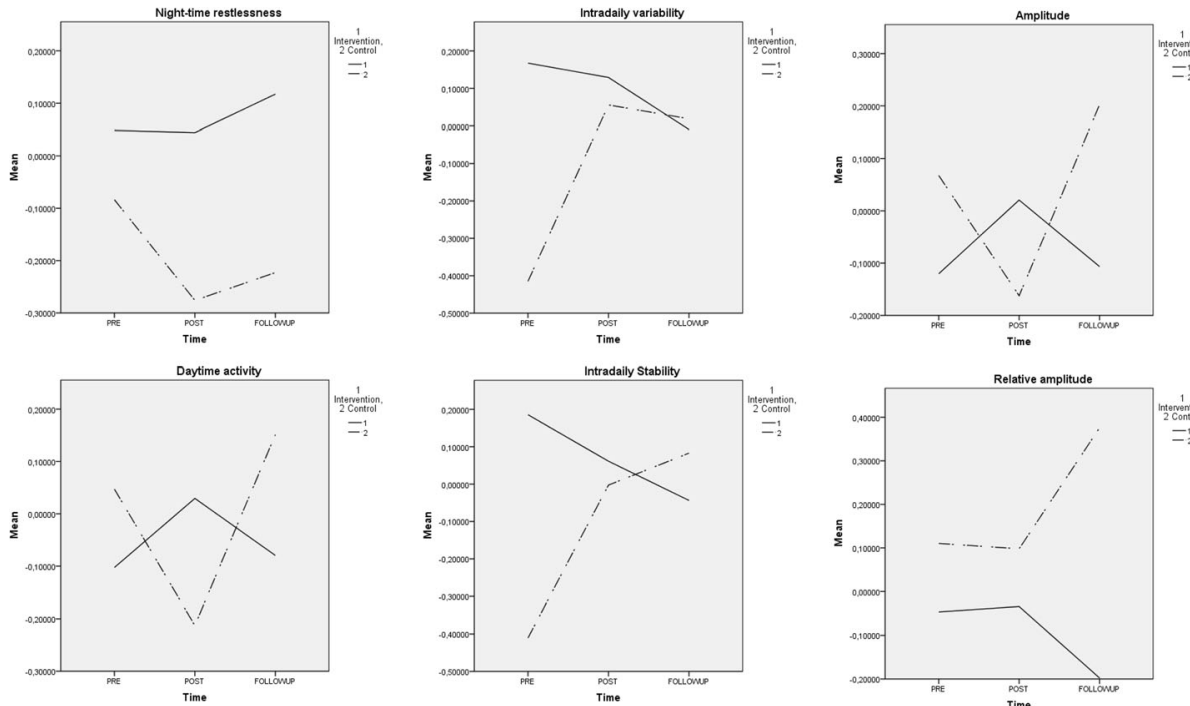

Intradaily stability
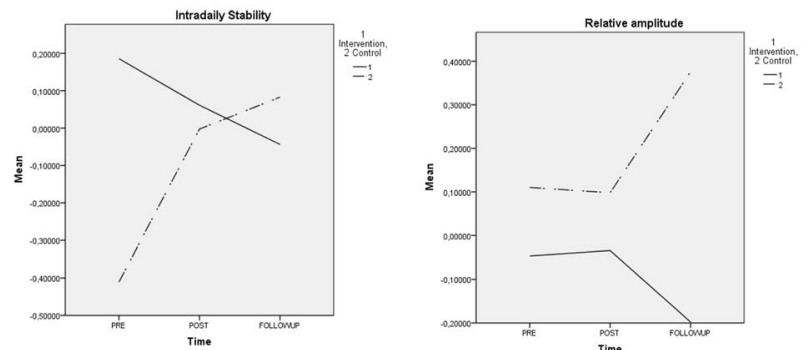
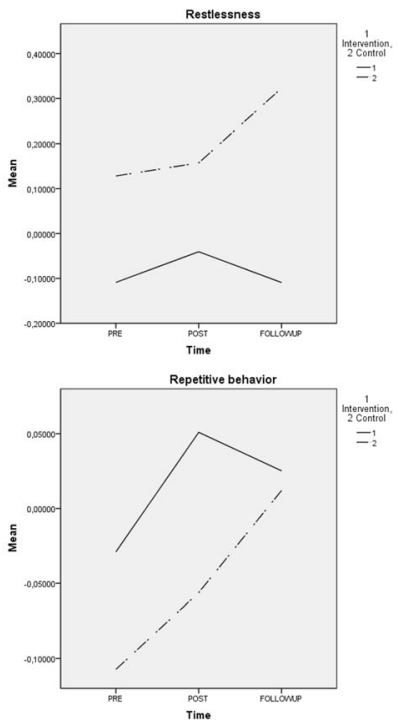

Fig. 2 Line graphs of all variables over time (standardized) 


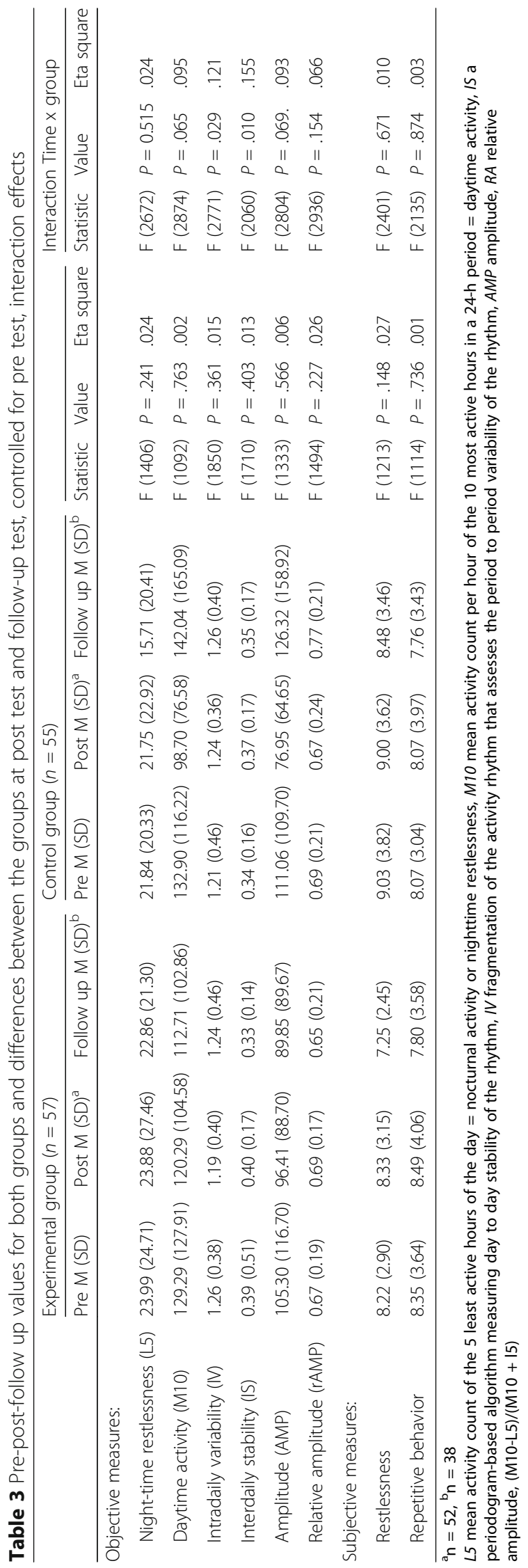


activity (.10), intradaily variability (.12), amplitude (.09) and relative amplitude (.07) and small for night time restlessness (.02).

\section{Subjective observation scores}

For means and standard deviations of the observation questionnaires, see Table 3. For line graphs, see Fig. 2.

\section{Main effects}

There are no significant differences between both groups for restlessness and repetitive behavior implicating there were no differences in observation scores comparing the small scaled homelike SCU and the regular SCU over time. The effect sizes are small.

\section{Interaction effects}

For both variables, restlessness and repetitive behavior, there are no significant interaction effects between groups. The effect sizes (95\% CI, time* group) for restlessness (.01) and repetitive behavior (.003) are small.

\section{Discussion}

The present study examined whether residents with moderate to severe dementia who transferred from a regular SCU to a small scale homelike SCU would show improvements in their circadian rest-activity rhythm, measured by actigraphy and by intersubjective activity reports from caregivers. It is known that an improved rest-activity rhythm may have positive effects on quality of life for residents with dementia [2].

Our results did not show significance main effects and low effect sizes in any of the actigraphy variables. There were two significant time*group interaction effects showing a better rest-activity pattern within $24 \mathrm{~h}$ for the experimental group and a more stable rhythm between days for the control group. These findings are in contrast to our expectation, that was based on, among others, prior evidence that a better sleep-wake rhythm might arise from factors such as increased activity at daytime, increased personal contact and social interactions $[9,23,27]$ and a quiet and dark sleeping environment [45]. One explanation of our findings compared to other studies can be a difference in used intervention. One study, for example, used a 30 min walk five times a week during 6 weeks [42] whereas in our study residents were encouraged to engage more in household activities. In the present study the residents of the intervention and control group could use comparable physical space with large walking circuits during all measures which can explain the absence of differences. So, not only the quantity of daytime activity, measured with actigraphy, but also the type of activity can account for (the lack of) outcomes. Further research is needed to evaluate the effects in quantity and quality of daytime activity for residents with dementia.

Besides this, the type of social intervention can differ in therapeutic modality; more one-to-one social interaction by family members [32] compared to, in our study, a training of the nursing personnel in psychosocial treatment. So, the type and quality of social interactions, for example (the type of) person centered care [46] or involvement by family members $[47,48]$ also can account for differences in care facilities. Further research exploring aspects of quality in relation to the quantity of social interactions can contribute to more specific therapeutic interventions in dementia care.

It is also possible that the relocation itself has caused the initial effect.

Effect sizes (interaction effect) vary from large to small and show mixed tendencies.

Observation scores of the nursing staff also showed no significant differences between the groups for restlessness and repetitive behavior for the residents with moderate to severe dementia. The perception by nursing staff of the rest-activity rhythm of residents with dementia can differ from the objective actigraph measures [12]. However, in this research the subjective and objective findings are in the same direction. The difference in findings between the studies can be explained by the use of different devices for the actigraphic (e.g. manufacturer or type) data and different subjective measures (type of observation measure).

The impact of environmental interventions as small scaled homelike SCU's or light therapy on rest- activity of residents with dementia is mixed [2]. One can assume that just the differences in environment matter is too small and the measuring period too short to sort any effect on the resident with dementia [49]. A different environment can probably generate an effect in restactivity and should perhaps be related to, for example, behavioral problems in residents with dementia [21]. Perhaps longitudinal research with repeated measurements for an extended period of time can detect the impact of environmental interventions. The question arises whether small scaled facilities attribute to better care or e.g. to the used furniture and equipment and colors in the accommodation.

\section{Limitations}

The use of actiwatches as device in our study shows limitations such as data loss, effects due to wearing of the device and usability for residents with dementia [34]; drop out, were death, removal of actiwatches, or verbal or non-verbal resistance whereby we did not collect good contiguous periods of data [50, 51]. For a field study like this however, the maximum achievable data was collected. 
Besides that, the actigraphy parameters of the used (older) actiwatches is possibly not refined enough to detect differences. Newer actiwatch versions can show more specific data and therefore more information about rest-activity rhythms of the residents with dementia [48-52]. The best practice however is the use of objective methods as well as intersubjective observational data collected from the nursing staff simultaneously $[12,40]$. In dementia care, it is almost never possible to retrieve subjective information directly from the resident with dementia [34].

The current study focused on rest-activity patterns of residents with dementia and the effect of different care facilities. Further research is needed to look at other possible benefits on for example quality of life or medication use of care situations in relation to dementia.

This study is part two of a larger study performed on the same population [39]. In future articles, results about medication use, quality of life, mood and social behavior will be presented.

\section{Conclusion}

The results show mixed differences in rest-activity for residents with moderate to severe dementia living in a small scaled homelike SCU compared with a regular SCU over time.

Longitudinal research with polysomnography and larger groups is recommended.

\section{Abbreviations}

AMP: Amplitude; Cl: Confidence interval; IS: Interdaily stability; IV: Intradaily variability; L5: Min/h activity in least active 5 h; M10: Min/h activity in most active 10 h; rAMP: relative amplitude, (M10-L5)/(M10 + I5); SCU: Special Care Unit

\section{Acknowledgements}

We are very thankful to all family members, residents and staff of the SCU's for their participation.

\section{Funding}

This study was not supported by any sponsor.

\section{Availability of data and materials}

The dataset used for this article is available on request. For further information on this database, you may contact the PI of the survey, J.S. Kok (js.kok@lentis.nl).

\section{Authors' contributions}

Conceived and designed the experiments: JSK EJAS. Performed the experiments: JSK. Analyzed the data: JSK CGB. Wrote the paper: JSK IB EJAS. Critical reading: CGB. Conceived and designed the original study: JSK EJAS. All authors read and approved the final manuscript.

\section{Ethics approval and consent to participate}

All legal representatives of the residents signed an informed consent prior to the measurements and were informed of the goal and procedure of the study. Before each measurement, the residents were invited to assent. By resistance of any kind of the resident, no measurements were conducted. The study has been approved by the Ethical Committee of the department of Psychology of the University of Groningen, the Netherlands (no. PPO008093), registered 3 June 2009.
Consent for publication

Not applicable.

\section{Competing interests}

The authors declare that they have no (financial) competing interests.

\section{Publisher's Note}

Springer Nature remains neutral with regard to jurisdictional claims in published maps and institutional affiliations.

\section{Author details}

'Lentis|Dignis, Mental Health Care Institute, PO Box 128, 9470 AC, Zuidlaren, The Netherlands. ${ }^{2}$ Department of Clinical Neuropsychology, VU University Amsterdam, van der Boechorstraat 1, 1081 BT, Amsterdam, The Netherlands.

Received: 4 January 2017 Accepted: 26 June 2017

Published online: 05 July 2017

\section{References}

1. Crowley K. Sleep and sleep disorders in older adults. Neuropsychol Rev. 2011:21:41-53. doi:10.1007/s11065-010-9154-6.

2. Musiek ES, Xiong DD, Holtzman DM. Sleep, circadian rhythms, and the pathogenesis of Alzheimer Disease. Experimental \& Moleculair Medicine 2015 47, el48; doi:10.1038/emm.2014.121.

3. Ju YE, Lucey BP, Holtzman DM. Sleep and Alzheimer disease pathology-a bidirectional relationship. Nat Rev Neurol 2014 Feb;10(2):115-119. doi:10.1038/nrneurol.2013.269. Epub 2013 Dec 24.

4. Peter-Derex L, Yammine P, Bastuji H, Croisile B. Sleep and Alzheimer's disease. Sleep Med Rev. 2015 Feb;19:29-38. doi:10.1016/j.smrv.2014.03.007.

5. Hooghiemstra AM, Eggermont LHP, Scheltens $P$, van der Flier WM, Scherder EJA. The rest-activity rhythm and physical activity in early-onset dementia. Alzheimer Dis Assoc Disord. 2015;29:45-9.

6. Vecchierini MF. Sleep disturbances in Alzheimer's disease and other dementias. Psychol Neuropsychiatr Vieil. 2010 Mar;8(1):15-23. doi:10.1684/pnv.2010.0203

7. Bombois S, Derambure P, Pasquier F, Monaca C. Sleep disorders in aging and dementia. J Nutr Health Aging. 2010 Mar;14(3):212-7.

8. McCurry SM, Ancoli-Israel S. Sleep dysfunction in Alzheimer's disease and other dementias. Curr Treat Options Neurol. 2003 May;5(3):261-72.

9. Zhou QP, Jung L, Richards KC. The management of sleep and circadian disturbance in patients with dementia. Curr Neurol Neurosci Rep. 2012 Apr;12(2):193-204. doi:10.1007/s11910-012-0249-8.

10. Merrilees J, Hubbard E, Mastick J, Miller BL, Dowling GA. Rest-activity and behavioral disruption in a patient with frontotemporal dementia. Neurocase. 2009 Dec:15(6):515-26. doi:10.1080/13554790903061371.

11. Kim SS, Oh KM, Richards K. Sleep disturbance, nocturnal agitation behaviors, and medical comorbidity in older adults with dementia: relationship to reported caregiver burden. Res Gerontol Nurs. 2014 Sep-Oct;7(5):206-14. doi:10.3928/19404921-20140512-01.

12. Landry GJ, Best JR, Liu-Ambrose T. Measuring sleep quality in older adults: a comparison using subjective and objective methods. Front Aging Neurosci. 2015 Sep 7;7:166. doi:10.3389/fnagi.2015.00166.

13. Coogan AN, Schutová B, Husung S, Furczyk K, Baune BT, Kropp P, Häsler TJ. The circadian system in Alzheimer's disease: disturbances, mechanisms, and opportunities. Biol Psychiatry. 2013;74:333-9. doi:10.1016/j.biopsych.2012.11.021.

14. Desai AK, Schwartz L, Grossberg GT. Behavioral disturbance in dementia. Curr Psychiatry Rep. 2012 Aug;14(4):298-309. doi:10.1007/s11920-012-0288-5.

15. Elcombe EL, Lagopoulos J, Duffy SL, Lewis SJ, Norrie L, Hickie IB, Naismith $\mathrm{SL}$. Hippocampal volume in older adults at risk of cognitive decline: the role of sleep, vascular risk, and depression. J Alzheimers Dis. 2015;44(4):1279-90. doi:10.3233/JAD-142016

16. Guarnieri B, Sorbi S. Sleep and cognitive decline: a strong bidirectional relationship. It is time for specific recommendations on routine assessment and the Management of Sleep Disorders in patients with mild cognitive impairment and dementia. Eur Neurol. 2015;74(1-2):43-8. doi:10.1159/000434629.

17. Miller MA, Wright H, Hough J, Cappuccio FP (2014). Sleep and cognition, sleep and its disorders affect society, Idzikowski C (Ed.), InTech, doi:10.5772/58735.

18. Lim AS, Yu L, Kowgier M, Schneider JA, Buchman AS, Bennett DA. Modification of the relationship of the apolipoprotein $E \varepsilon 4$ allele to the risk 
of Alzheimer disease and neurofibrillary tangle density by sleep. JAMA Neurol. 2013 Dec;70(12):1544-51. doi:10.1001/jamaneurol.2013.4215.

19. Shin HY, Han HJ, Shin DJ, Park HM, Lee YB, Park KH. Sleep problems associated with behavioral and psychological symptoms as well as cognitive functions in Alzheimer's disease. J Clin Neurol. 2014 Jul;10(3):203-9. doi:10.3988/jen.2014.10.3.203.

20. Cermakian N, Lamont EW, Boudreau P, Boivin DB. Circadian clock gene expression in brain regions of Alzheimer 's disease patients and control subjects. J Biol Rhythm. 2011 Apr;26(2):160-70. doi:10.1177/ 0748730410395732.

21. Kok JS, Berg IJ, Scherder EJ. Special care units and traditional care in dementia: relationship with behavior, cognition, functional status and quality of life - a review. Dement Geriatr Cogn Dis Extra. 2013 Oct 5;3(1): 360-75. doi:10.1159/000353441.

22. Figueiro MG, Plitnick BA, Lok A, Jones GE, Higgins P, Hornick TR, Rea MS. Tailored lighting intervention improves measures of sleep, depression, and agitation in persons with Alzheimer's disease and related dementia living in long-term care facilities. Clin Interv Aging. 2014 Sep 12;9:1527-37. doi:10.2147/CIA.S68557.

23. Deschenes $\mathrm{CL}$, McCurry SM. Current treatments for sleep disturbances in individuals with dementia. Curr Psychiatry Rep. 2009 Feb;11(1):20-6.

24. Then FS, Luppa M, Schroeter ML, König H-H, Angermeyer MC, Riedel-Heller SG. Enriched environment at work and the incidence of dementia: results of the Leipzig longitudinal study of the aged (LEILA 75+). PLoS One. 2013 July;8(7):e70906. doi:10.1371/journal.pone.0070906.

25. Vermeerbergen L, Van Hootegem G, Benders J. A comparison of working in small-scale and large-scale nursing homes: A systematic review of quantitative and qualitative evidence. Int J Nurs Stud. 2017 Feb;67:59-70. doi:10.1016/j.ijnurstu.2016.11.006 Epub 2016 Nov 2013.

26. Schnelle JF, Alessi CA, Al-Samarrai NR, Fricker RD Jr, Ouslander JG. The nursing home at night: effects of an intervention on noise, light, and sleep. J Am Geriatr Soc. 1999 Apr:47(4):430-8.

27. Gitlin LN, Kales HC, Lyketsos CG. Nonpharmacologic management of behavioral symptoms in dementia. JAMA. 2012 Nov 21;308(19):2020-9. doi:10.1001/jama.2012.36918.

28. Neikrug AB, Ancoli-Israel S. Sleep disturbances in nursing homes. J Nutr Health Aging. 2010 Mar;14(3):207-11.

29. Carvalho-Bos SS, Riemersma-van der Lek RF, Waterhouse J, Reilly T, Van Someren EJW. Strong association of the rest-activity rhythm with well-being in demented elderly women. Am J Geriatr Psychiatry 15:2, Februari 2007.

30. Eggermont LH, Blankevoort CG, Scherder EJ. Walking and night-time restlessness in mild-to-moderate dementia: a randomized controlled trial. Age Ageing. 2010 Nov;39(6):746-9. doi:10.1093/ageing/afq115.

31. Verbeek H, van Rossum E, Zwakhalen SM, Kempen GI, Hamers JP. Small, homelike care environments for older people with dementia: a literature review. Int Psychogeriatr. 2009 Apr;21(2):252-64. doi:10.1017/ S104161020800820X

32. O'Conner DW, Ames D, Gardner B, King M. Psychosocial treatment of behavior symptoms in dementia: a systematic review of reports meeting quality standards. Int Psychogeriatr. 2009 Apr;21(2):241-51. doi:10.1017/S1041610208008223.

33. Weldemichael DA Grossberg GT. Circadian Rhythm Disturbances in Patients with Alzhiemer's Disease: A Review. Int J Alzheimers Dis. 2010, Sep 2;2010. pii: 716453. doi:10.4061/2010/716453.

34. Brewster GS, Varrasse M, Rowe M. Sleep and cognition in communitydwelling older adults: a review of literature. Healthcare (Basel). 2015 Dec; 3(4):1243-70. doi:10.3390/healthcare3041243.

35. Folstein M, Folstein S, McHugh P. Mini-mental state: a practical method for grading the cognitive state of patients for de clinician. J Psychiatr Res. 1975;12:189-98.

36. Molloy DW, Alemayehu E, Roberts R. Reliability of a standardized Minimental state Examination compared with the traditional Mini-mental state Examination. Am J Psychiatry. 1991 Jan;148(1):102-5.

37. Yesavage J, Brink T, Rose T, Lum O, Huang V, Adey M, Leirer V. Development and validation of a geriatric depression screening scale: a preliminary report. J Psychiatr Res. 1982-1983;17(1):37-49.

38. Kok R, Heeren T, Hemert van A. De geriatric depression scale. Tijdschrift voor psychiatrie. 1993;35(6):416-21.

39. Kok JS, van Heuvelen MJ, Berg IJ, Scherder EJ. Small scale homelike special care units and traditional special care units: effects on cognition in dementia; a longitudinal controlled intervention study. BMC Geriatr. 2016 Feb 16;16:47. doi:10.1186/s12877-016-0222-5.

40. Most IS, Samir Aboudan MA, Scheltens P, van Someren EJW. Discrepancy between subjective and objective sleep disturbances in early- and moderate-stage Alzheimer disease. Am J Geriatr Psychiatry. 2012;20:6. doi:10.1097/JGP.0b013e318252e3ff.

41. Marino M, Li Y, Rueschman MN, Winkelman JW, Ellenbogen JM, Solet JM, Dulin H, Berkman LF, Buxton OM. Measuring sleep: accuracy, sensitivity, and specificity of wrist actigraphy compared to polysomnography. Sleep. 2013 Nov 1;36(11):1747-55. doi:10.5665/sleep.3142.

42. Verstraten $P$, van Eekelen C, Handleiding voor de Gedragsobservatieschaal voor intramurale psychogeriatrie. Van Loghum Slaterus, 1987.

43. Lakens D. Calculating and reporting effect sizes to facilitate cumulative science: a practical primer for t-tests and ANOVAs. Front Psychol. $2013 \mathrm{Nov}$ 26;4:863. doi:10.3389/fpsyg.2013.00863.

44. Robey R. Reporting point and interval estimates of effect-size for planned contrasts: fixed within effect analyses of variance. J Fluen Disord. 2004;29(4):307-41.

45. Miller MA. The role of sleep and sleep disorders in the development, diagnosis, and Management of Neurocognitive Disorders. Front Neurol. 2015 Oct 23;6:224. doi:10.3389/fneur.2015.00224.

46. Williams KN, Perkhounkova $Y$, Jao $Y L$, Bossen A, Hein M, Chung S, Starykowicz A, Turk M. Person-centered communication for nursing home residents with dementia. West J Nurs Res. 2017 Mar;1:193945917697226. doi:10.1177/0193945917697226.

47. Verbeek H, Zwakhalen SM, van Rossum E, Kempen Gl, Hamers JP. Smallscale, homelike facilities in dementia care: a process evaluation into the experiences of family caregivers and nursing staff. Int J Nurs Stud. 2012 Jan; 49(1):21-9. doi:10.1016/j.ijnurstu.2011.07.008.

48. Shata ZN, Amin MR, El-Kady HM, Abu-Nazel MW. Efficacy of a Multicomponent Psychosocial Intervention Program for Caregivers of Persons Living with Neurocognitive Disorders, Alexandria, Egypt: A randomized controlled trial. Avicenna J Med. 2017 Apr-Jun;7(2):54-63. doi:10.4103/2231-0770.203610.

49. Hart TL, Swartz AM, Cashin SE, Strath SJ. How many days of monitoring predict physical activity and sedentary behaviour in older adults? Int J Behav Nutr Phys Act. 2011 Jun 16;8:62. doi:10.1186/1479-5868-8-62.

50. van Someren EJ. Improving actigraphic sleep estimates in insomnia and dementia: how many nights? J Sleep Res. 2007 Sep;16(3):269-75.

51. Mantua J, Gravel N, Spencer RM. Reliability of Sleep Measures from Four Personal Health Monitoring Devices Compared to Research-Based Actigraphy and Polysomnography. Sensors (Basel). 2016 May 5;16(5). pii: E646. doi:10.3390/s16050646.

52. Martoni M, Bayon V, Elbaz M, Léger D. Using actigraphy versus polysomnography in the clinical assessment of chronic insomnia (retrospective analysis of 27 patients). Presse Med. 2012 Mar;41(3 Pt 1):e95-e100. doi:10.1016/j.lpm.2011.07.019.

53. Verhage F. Intelligence and age: research on Dutch people aged twelve to seventy seven years old. Assen: van Gorcum; 1964

\section{Submit your next manuscript to BioMed Central and we will help you at every step:}

- We accept pre-submission inquiries

- Our selector tool helps you to find the most relevant journal

- We provide round the clock customer support

- Convenient online submission

- Thorough peer review

- Inclusion in PubMed and all major indexing services

- Maximum visibility for your research

Submit your manuscript at www.biomedcentral.com/submit
C) Biomed Central 